\title{
Physiological Characteristics of Medicago sativa Seedlings in Response to Lab Simulated Basic Salt and Freeze-Thaw Stress
}

\author{
Guozhang Bao*, Jiancai Guo ${ }^{1 *}$ Bairu $\mathrm{Yan}^{2}$, Qi $\mathrm{Ao}^{3}$ \\ ${ }^{1}$ Key Laboratory of Groundwater Resources and Environment of the Ministry of Education (Jilin University); \\ Jilin Provincial Key Laboratory of Water Resources and Environment; College of New Energy and Environment, \\ Jilin University, Changchun, 130012 China \\ ${ }^{2}$ Environmental Monitoring Center Station of Jilin Province, Changchun, 130011 China \\ ${ }^{3}$ College of Environmental Science and Engineering, Peking University, Beijing, 100871 China
}

Received: 13 February 2021

Accepted: 21 September 2021

\begin{abstract}
Increasing levels of sodium carbonate are major causes of grassland alkalinization in the SongNen Plain of northeast China. In winter-spring alternation, plants are often subjected to double stresses of alkaline salt and freeze-thaw. Here, Medicago sativa CV. Zhongmu No.1 seedlings were used to study the effects of laboratory-simulated basic salt (BS) and freeze-thaw (FT) stresses on the contents of osmoregulatory substances, biological membrane permeability, and antioxidant enzyme activity. The results showed that under individual BS- or FT- stress, the soluble protein in seedlings decreased by 9.6-20.2\%, proline and MDA contents increased by $18.4-48.1$ and 7.8-37.7\%, respectively. Furthermore, the activities of SOD and POD increased by $6.2-24.9$ and $4.8-30.3 \%$, respectively. During the freezing and thawing cycles, both proline and MDA contents initially increased and then decreased; these observations contrasted with those for soluble protein content. Activities of SOD and POD increased in attempts to resist reactive oxygen species (ROS). Moreover, $M$. sativa CV. seedlings under combined stress of BS and FT showed significantly higher physiological responses than those under individual stress (BS- or FT- stress). The results of this study demonstrate the molecular basis for BS- and FT- stress tolerance by M. sativa. In turn, this could lead to strategies for further enhancement of these tolerances in the plant.
\end{abstract}

Keywords: Medicago sativa seedling, freeze-thaw, alkaline salt, physiological responses

e-mail: baogz@jlu.edu.cn 


\section{Introduction}

Soil salinization is an increasingly serious global problem caused by unreasonable exploitation and utilization of land, especially under the ravages of climate change. China is a country whose soils are severely threatened by salinization [1]. In the west of northeast China plains, saline land accounts for $10.44 \%$ of the total land area [2]. The Song-Nen Plain is a symbol of the northeast China plain where grassland salinization is often accompanied by freeze-thaw stress between spring and winter [3]. This dual ecological stress of salinization and freeze-thaw has an extensive impact on grassland plants in this area.

Medicago sativa $\mathrm{CV}$. is a leguminous plant that is known to have cold tolerance and moderate saline alkaline tolerance [4]. The purpose of this study is to investigate physiological responses of $M$. sativa $\mathrm{CV}$. under combined stress of freeze-thaw and alkaline conditions in soil. In this paper, our laboratorysimulated stresses are based on local environmental features of the Song-Nen Plain $[2,3] . \mathrm{Na}_{2} \mathrm{CO}_{3}$, one of the main salinization components, was artificially prepared to simulate alkaline salt stress with $60 \mathrm{mmol} / \mathrm{L}$ $\mathrm{Na}_{2} \mathrm{CO}_{3}$ solution. Seedlings of $M$. sativa were subjected to combined stress of freeze-thaw and basic salt. The contents of proline, soluble protein and malonaldehyde (MDA) and activities of superoxide dismutase (SOD) and peroxidase (POD) in seedlings were determined in each temperature stage.

\section{Materials and Methods}

\section{M. sativa $\mathrm{CV}$. Seedlings}

Full size, uniform $M$. sativa seeds were soaked in $0.1 \%$ acidic $\mathrm{KMnO}_{4}$ solution for $2 \mathrm{~h}$ and washed with distilled water, then seeds were arranged in glass culture dishes covered with two layers of filter paper adding Hoagland nutrient solution [5], 100 pieces or so in each disc. Seedling cultivation in the entire process was carried out in a MGC-450BP light incubator (Shanghai Yiheng Scientific Instruments Co., Ltd) set at $25^{\circ} \mathrm{C}$ in the daytime and $15^{\circ} \mathrm{C}$ at night with $10 \mathrm{~h}$ light and $14 \mathrm{~h}$ dark. Appropriate amount of Hoagland nutrient solution was added twice during the germination per day. Zhang et al. showed that seedling stage was the optimum stage for salt tolerance identification [6]. The seedlings were cultured for 5 days until they grew to about $5 \mathrm{~cm}$ and they could be prepared for later experiments.

\section{Preparation of $\mathrm{Na}_{2} \mathrm{CO}_{3}$ Solution}

Sodium carbonate is the main component of alkaline soils; alkalinity is one of the main limiting factors of seedlings growth in alkaline soils [7]. The experiment used $60 \mathrm{mmol} / \mathrm{L} \mathrm{Na}_{2} \mathrm{CO}_{3}$ solution. We chose this concentration to fall between little to serious damage to seedlings. Additionally, it reflected the practical range of alkalinity in the region as well.

\section{Experiment of Basic Salt Stress $\left(\mathrm{Na}_{2} \mathrm{CO}_{3}\right.$ Solution)}

The seedlings were divided into two groups, alkaline salt treatment group and control group. $450 \mathrm{~mL}$ of $\mathrm{Na}_{2} \mathrm{CO}_{3}$ solution was added to alkaline salt treatment group and same volume of water was added to the control group; each group was cultivated for one day. The cultivated condition was as the same as seedling cultivation.

\section{Experiment of Freeze-Thaw Stress}

The seedlings were divided into four treatments (CK: no treatment, BS stress: basic salt stress only, FT stress: freeze-thaw stress only and BS+FT stress: combined stress of freeze-thaw and basic salt), Table 1. Only FT stress and BS+FT stress treatments were put into BPHJ-120A high-low-temperature test chamber (Shanghai Yiheng Scientific Instruments Co., Ltd) for freezing and thawing processes, while $\mathrm{CK}$ and BS stress treatments were maintained in light incubator under previous cultivated condition.

The temperature in high-low-temperature test chamber was decreased from $15^{\circ} \mathrm{C}$ to $-5^{\circ} \mathrm{C}$ at a speed of $2.5^{\circ} \mathrm{C} / \mathrm{h}$ as freezing stage, and increased from $-5^{\circ} \mathrm{C}$ to $10^{\circ} \mathrm{C}$ at the same speed as thawing stage. After the freeze-thaw cycle started, five parallel samples were taken every 2 hours from four treatments at random and they were labeled as T1, T2...T7 (Table 2) for determination of physiological indicators. Thus, samples' temperature of FT stress and BS+FT stress was $10,5,0,-5,0,5,10^{\circ} \mathrm{C}[8]$, while that of $\mathrm{CK}$ and BS stress was $15^{\circ} \mathrm{C}$ as a constant temperature (Table 2). All the samples were firstly wrapped up with tin foil paper, secondly fixed in liquid nitrogen immediately for $50 \mathrm{~s}$ and finally put into the ultra-lowtemperature freezer at $-80^{\circ} \mathrm{C}$ for storage in order to measure the contents of proline, soluble protein, MDA, SOD and POD activities.

\section{Determination of Physiological Indicators}

\section{Proline Content}

Free-proline is one of the most important osmoregulatory substances of plants [9]. It accumulates

Table 1. Experimental design of treatments under stress.

\begin{tabular}{|c|c|c|c|c|}
\hline & CK & BS & FT & BS+FT \\
\hline Freeze-thaw stress & - & - & + & + \\
\hline Basic salt stress & - & + & - & + \\
\hline
\end{tabular}

+ add stress; - no stress 
Table 2. Temperature changes of parallel samples in treatments with time.

\begin{tabular}{|c|c|c|c|c|c|c|c|c|}
\hline \multirow{2}{*}{ Treatments } & T1 & T2 & T3 & T4 & T5 & T6 & T7 \\
\cline { 3 - 9 } & $2 \mathrm{~h}$ & $4 \mathrm{~h}$ & $6 \mathrm{~h}$ & $8 \mathrm{~h}$ & $10 \mathrm{~h}$ & $12 \mathrm{~h}$ & $14 \mathrm{~h}$ \\
\hline \multirow{2}{*}{$\mathrm{CK} ; \mathrm{BS}$} & \multirow{2}{*}{ Temperature $\left({ }^{\circ} \mathrm{C}\right)$} & 15 & 15 & 15 & 15 & 15 & 15 & 15 \\
\cline { 3 - 10 } & 10 & 5 & 0 & -5 & 0 & 5 & 10 \\
\hline
\end{tabular}

constantly to reduce plant water potential and prevent cells from losing water [10]. Furlan et al. have studied that the accumulation of proline was caused by abiotic stress and proline played a role in stress protection [11]. Acidic ninhydrin colorimetric method was used to determine proline content [12].

\section{Soluble Protein Content}

Soluble protein is an important group of osmoregulatory substances that confers stress resistance to plants. Soluble protein possesses a strong ability to promote cellular-bound water, which allows cells to resist protoplasm damages from freezing temperatures [13]. Soluble protein confers strong stress resistance to plants; however this ability is affected by the different stresses [14]. Coomassie brilliant blue colorimetric method was used to determine soluble protein content [15].

\section{MDA Content}

Malondialdehyde (MDA) is a major product of lipid peroxidation of cell membranes; its accumulation in tissue is an indicator of cell damage and death [16]. Reactive oxygen stimulated by salinity stress causes cell membrane function disorder because of destruction of cell cytoskeleton [17]. When plants are subjected to multiple stressors, MDA will be first affected by temperature factor. Low temperature below $0^{\circ} \mathrm{C}$ mainly leads to cell freezing damage. Thiobarbituric acid method was used to determine malondialdehyde (MDA) content [18].

\section{SOD Activity}

Superoxide dismutase (SOD) activity can reflect plant's resistance to toxic levels of reactive oxygen species (ROS) in its cells. Increasing levels of SOD can modulate to some point, ROS-mediated damage caused by plasma membrane peroxides [19].

\section{POD Activity}

Peroxidase (POD) is a protective enzyme for plant cells. Its activity can reflect cold resistance of plants. The POD in protective enzyme system of cells enzymatically degrades the $\mathrm{H}_{2} \mathrm{O}_{2}$, so that plants can resist the damage of hazardous substances during the metabolic processes in adversity, showing their resistance [20]. SOD and POD activities were determined by SOD and POD kits provided by Nanjing Jiancheng Biological Institute.

\section{Statistical Analysis}

In data processing, Microsoft Excel 2016 and R 3.3.1 statistical software (R Foundation for Statistical Computing, Vienna, Austria) were used for statistics and analysis. The significance level was at 0.05 , and all of the results were presented as mean $( \pm)$ SE. The mean values along with the standard error $( \pm)$ were shown in the bar charts drawn by using Origin 8.0 software.

\section{Results and Discussion}

Changes of Osmoregulatory Substances

\section{Proline Content}

The maximum and minimum proline of seedlings was $182.25 \mu \mathrm{g} \cdot \mathrm{g}^{-1}$ and $71.59 \mu \mathrm{g} \cdot \mathrm{g}^{-1}$, respectively (Fig. 1). Proline contents of seedlings in BS-, FT- and BS+FT stress groups initially increased and then they decreased $(P<0.05)$, compared with $\mathrm{CK}$ group. Meanwhile, with temperature decreasing, from $10^{\circ} \mathrm{C}$ to $-5^{\circ} \mathrm{C}$ (T1-T4), proline contents of seedlings under BS-, FT- and BS+FT

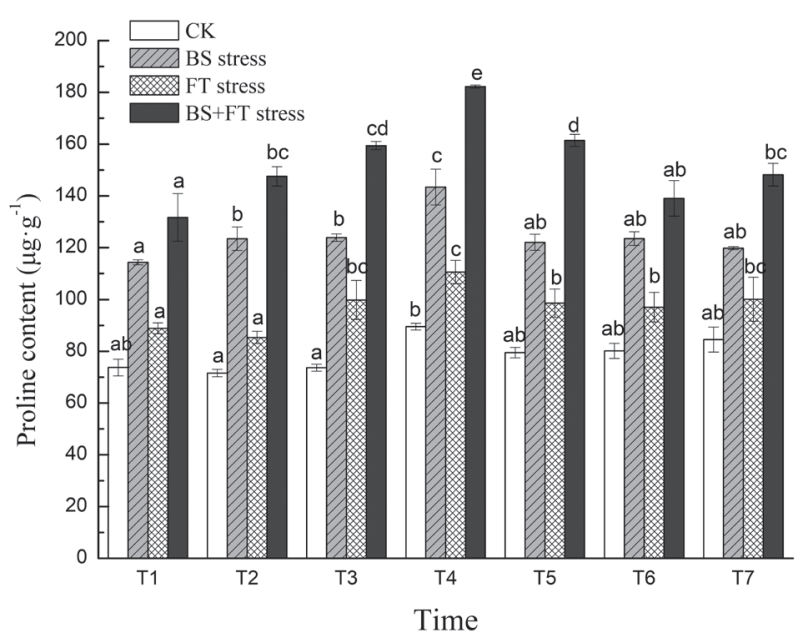

Fig. 1 Effects of basic salt and freeze-thaw stress on proline content in seedlings. 


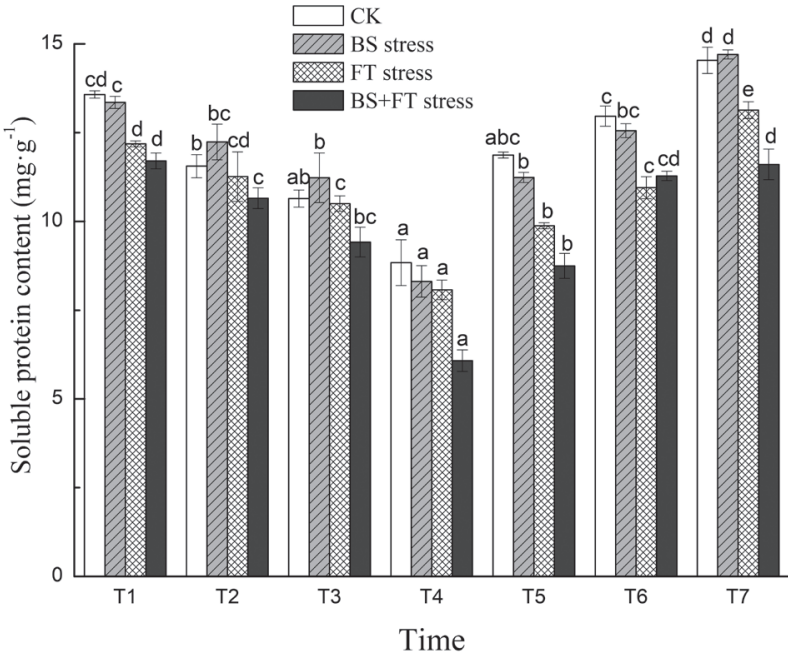

Fig. 2 Effects of basic salt and freeze-thaw stress on soluble protein content in seedlings.

stress increased by $25.4,29.6$ and $38.4 \%$, respectively. The proline content of seedlings under BS+FT stress was significantly higher than the other groups $(P<0.05)$. At thawing stage (T4-T7), proline contents of seedlings under BS- and BS+FT stress decreased by 16.5 and $23.7 \%$, respectively. However, from $\mathrm{T} 5$ to $\mathrm{T} 7$, there was no significant difference between BS- and FT stress groups. Besides, the basic salt stress was more intense than freeze-thaw stress. Additionally, effects of combined stress of freeze-thaw and basic salt were stronger than those of individual stress. It had obvious correlation with temperature which was consistent with Bian et al.'s [21] research. However, Poustini et al. [22] have found that there may be no correlation between proline and salt tolerance which is the opposite of Mansour et al. [23]. The specific correlation needs to be further studied.

\section{Soluble Protein Content}

From Fig. 2, it can be seen that soluble protein content of highest was $14.70 \mathrm{mg} \cdot \mathrm{g}^{-1}$, and the lowest was $6.08 \mathrm{mg} \cdot \mathrm{g}^{-1}$. The value of BS+FT stress group significantly decreased sharply compared with CK group $(P<0.05)$. During the freezing stage, soluble protein content of seedlings under BS+FT stress went up as temperature dropped, whereas at thawing stage, it ascended significantly. At freezing stage (T1-T4), with the temperature going down, soluble protein contents of seedlings under BS-, FT- and BS+FT stress decreased by $37.8,33.8$ and $48.1 \%$, respectively. Meanwhile soluble protein content of seedlings under $\mathrm{BS}+\mathrm{FT}$ stress was significantly lower than CK group $(P<0.05)$. At thawing stage (T4-T7), soluble protein contents of seedlings under BS-, FTand BS+FT stress increased by $64.5,77.0$ and $90.9 \%$, respectively.

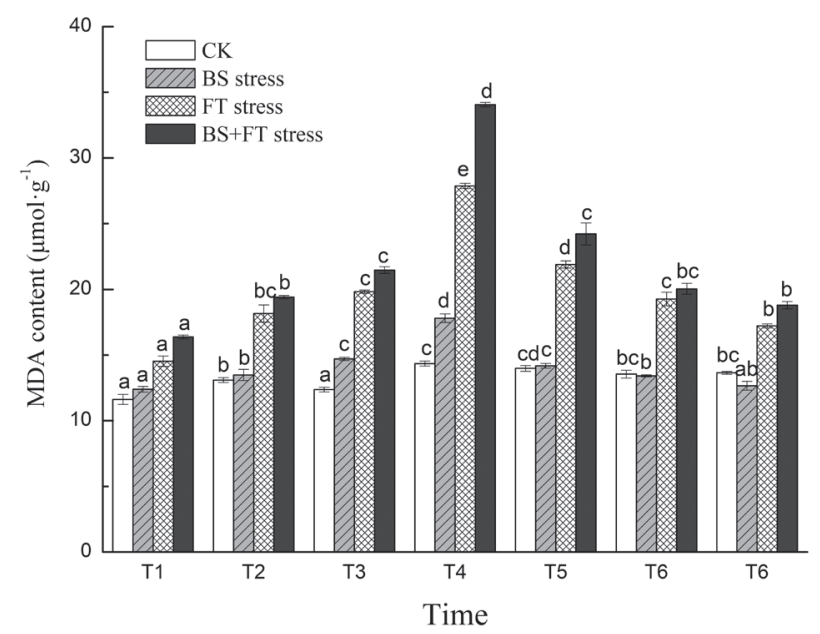

Fig. 3 Effects of basic salt and freeze-thaw stress on MDA content in seedlings.

\section{Changes of Biological Membrane Permeability}

\section{MDA Content}

The MDA content of seedlings in each group reached its maximum value in T4 ( Fig. 3), which was $14.35,17.81,37.06$, and $33.86 \mu \mathrm{mol} \cdot \mathrm{g}^{-1}$, respectively; these were significantly different from those of other times $(P<0.05)$. MDA contents under FT- and BS+FT stress had a similar trend that a first increase and then a gradual decrease compared with CK and BS stress from T1 to T7. During freezing stage (T1-T4), MDA contents of seedlings under BS-, FT- and BS+FT stress increased by 43.6, 155.1 and $106.7 \%$, respectively. Besides, MDA content of BS+FT stress was obviously higher than that of CK, BS- and FT stress. At thawing stage (T4-T7), with temperature rising back, MDA contents of seedlings under BS-, FT- and BS+FT stress decreased by $28.9,115.2$ and $80.2 \%$, respectively. However, there was no significant difference between T5, T6 and T7 temperature in $\mathrm{CK}$ and $\mathrm{BS}$ stress groups $(P>0.05)$.

\section{Changes of Antioxidant Enzymes}

\section{SOD Activity}

The maximum and minimum of SOD activity of seedlings was $1030.09 \mathrm{U} \cdot \mathrm{mg}^{-1}$ protein and $824.97 \mathrm{U} \cdot \mathrm{mg}^{-1}$ protein, respectively (Fig. 4). And SOD activity in each group reached its peak in T4. With the changes of time, the activity of SOD initially increased and then decreased. At freezing stage (T1-T4), SOD activities of seedlings under BS-, FT- and BS+FT stress increased by $15.9,13.0$ and $19.2 \%$, respectively. Both FT- and BS+FT stress groups had an increasing trend as the temperature fell from $10^{\circ} \mathrm{C}$ to $-5^{\circ} \mathrm{C}$. At thawing stage (T4-T7), SOD activities of seedlings under BS-, FTand BS+FT stress decreased by $8.6,6.5$ and $13.2 \%$, respectively. Though BS-, FT- and BS+FT stress groups 


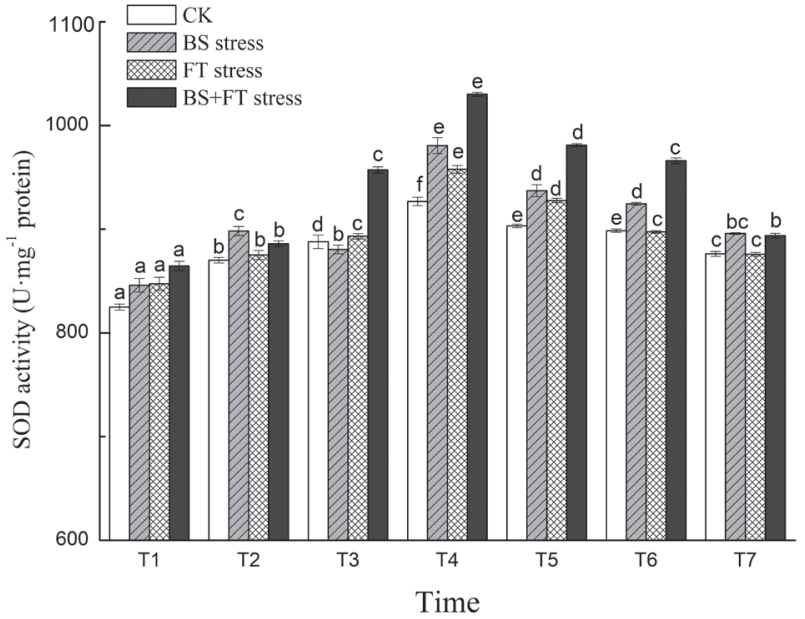

Fig. 4 Effects of basic salt and freeze-thaw stress on SOD activity in seedlings.

had a decreasing trend from $-5^{\circ} \mathrm{C}$ to $10^{\circ} \mathrm{C}$, there was no significant difference between T5 and T6 in BS stress group as well as between T6 and T7 in FT stress group $(P>0.05)$.

\section{POD Activity}

From Fig. 5, in freeze-thaw circle, both FT- and BS+FT stress groups had a similar trend that the value of POD activity increased initially and then decreased and finally stayed stable, which was similar to SOD activity. The maximum and minimum of POD activity of seedlings was $7.91 \mathrm{U} \cdot \mathrm{mg}^{-1}$ protein and $3.42 \mathrm{U} \cdot \mathrm{mg}^{-1}$ protein, respectively. POD activities under BS-, FT- and $\mathrm{BS}+\mathrm{FT}$ stress simultaneously peaked at $6.20 \mathrm{U} \cdot \mathrm{mg}^{-1}$ protein, $7.02 \mathrm{U} \cdot \mathrm{mg}^{-1}$ protein, $7.91 \mathrm{U} \cdot \mathrm{mg}^{-1}$ protein in $\mathrm{T} 4$. At freezing stage (T1-T4), POD activities of seedlings under BS-, FT- and BS+FT stress increased by 79.6,

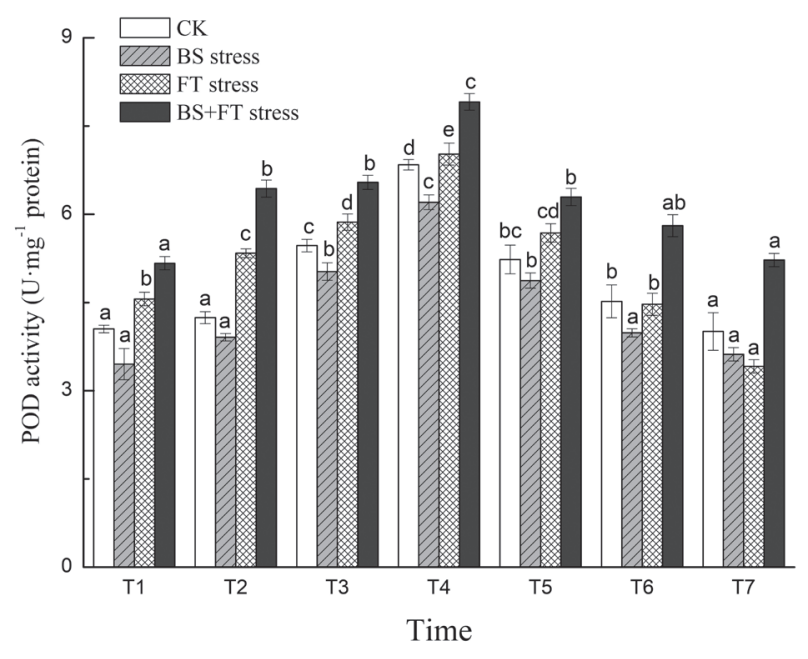

Fig. 5 Effects of basic salt and freeze-thaw stress on POD activity in seedlings.
54.0 and $53.1 \%$, respectively. It was worth mentioning that the growth rate of BS stress group was larger than that of CK, but its value was lower than that of CK. At thawing stage (T4-T7), POD activities of seedlings under BS-, FT- and BS+FT stress decreased by 41.6, 51.4 and $34.0 \%$, respectively. When the temperature was reduced from $10^{\circ} \mathrm{C}$ to $-5^{\circ} \mathrm{C}$ and then went back to $10^{\circ} \mathrm{C}$, there were significant differences between $\mathrm{T} 4$ and T7 in BS-, FT- and BS+FT stress groups $(P<0.05)$.

\section{Difference Analysis and Correlation Analysis}

Based on the results, the effects of stressors on five indicators (proline, soluble protein, MDA, SOD, POD) in $\mathrm{T} 4$ were the most intense. It was because that $\mathrm{CK}$ and the other three groups all reached a maximum (proline, MDA, SOD and POD) and minimum (soluble protein) in T4. We used different analysis method to estimate the effects of stressors on five indicators of alfalfa seedling. It can be seen that proline under BS-, FT- and BS+FT stress respectively increased significantly $(P<0.05)$ and proline under BS+FT stress changed most significantly, but BS- and FT stress had no significant difference (Fig. 6a). Compared with CK, BS+FT stress had the greatest impact, followed by BS stress and FT stress (BS+FT stress $>$ BS stress $>$ FT stress) (Fig. 6a). This result was similar to conclusion reported by Bao et al. [24]. The soluble protein of BS- and FT stress had no significant difference compared with $\mathrm{CK}$, but that of combined stress decreased significantly compared with CK (Fig. 6b). Moreover, MDA content was most affected by freeze-thaw stress, followed by combined stress and basic salt stress compared with CK (Fig. 6c). SOD activity had similar trends with proline (Fig. 6d). POD activity of BS+FT stress increased significantly and that of BS stress decreased significantly compared with CK $(P<0.05)$, but there was no significant difference between freeze-thaw stress and $\mathrm{CK}$ (Fig. 6d). The above results indicated that combined stress had a more intense impact on alfalfa seedlings than the individual stress, and basic salt stress had a more significant impact on seedlings than freeze-thaw stress.

Pearson correlation analysis was conducted on five indicators (proline, soluble protein, MDA, SOD, POD) of alfalfa seedling. The results revealed that proline had no correlation with soluble protein, MDA, SOD activity, and POD activity (Table 3). The soluble protein was negatively correlated with MDA, SOD activity and POD activity with correlation coefficients of $-0.817(P<0.01)$ and $-0.837(P<0.05),-0.626(P<0.05)$, respectively. MDA was positively correlated with SOD activity and POD activity, with correlation coefficients of $0.695(P<0.01)$ and $0.785(P<0.05)$. SOD activity was positively correlated with POD activity $(P<0.05)$. The results indicated that under basic salt stress and freeze-thaw stress, oxygen-free radicals accumulated in seedlings, along with membrane lipid peroxidation. These events were reflected by increasing contents of 

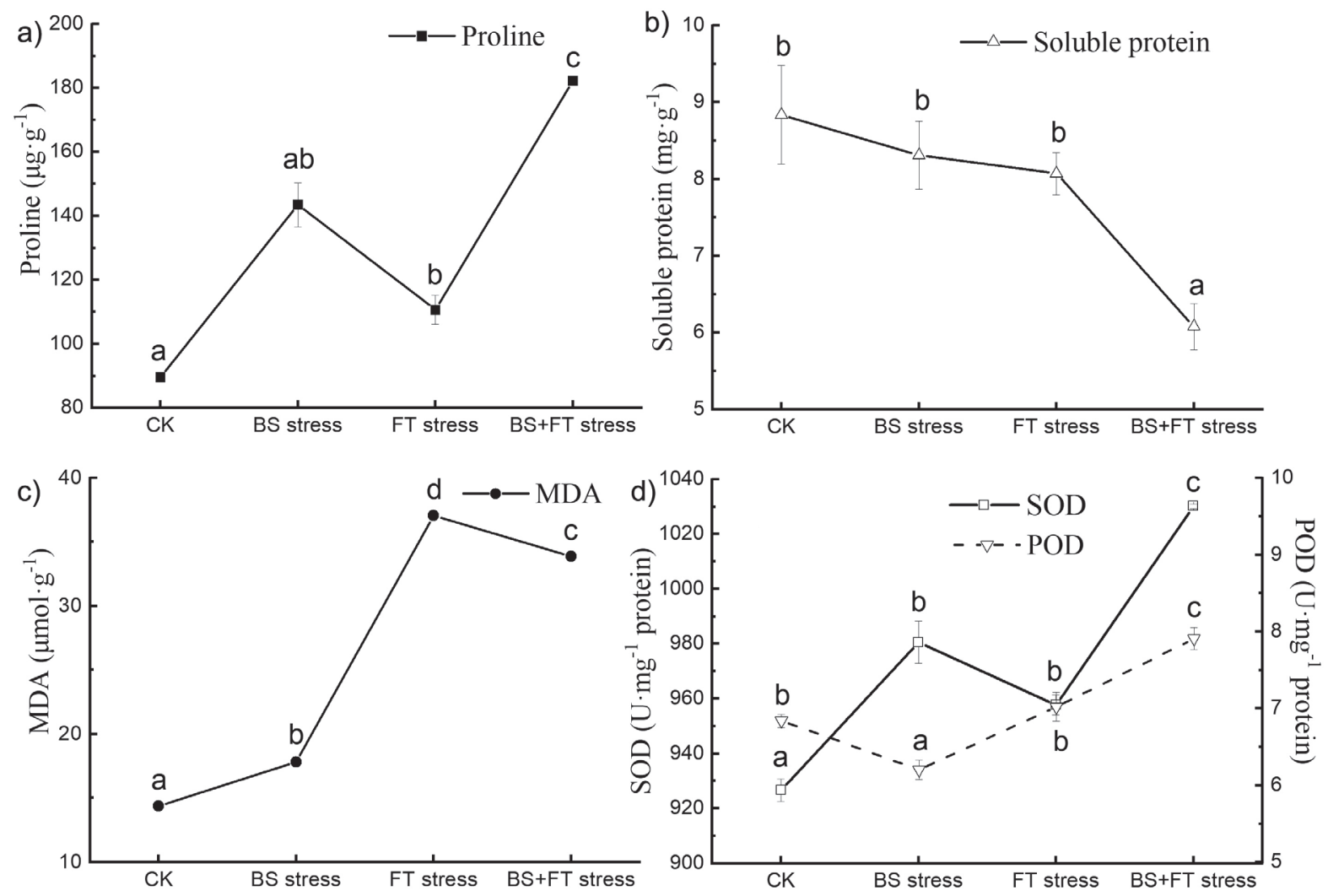

Fig. 6 Difference analysis between basic salt and freeze-thaw stress at T4 stage.

proline and MDA, as well as enhancements in SOD and POD antioxidant activities.

\section{Discussion of Changes in Osmoregulatory Substances}

The two indicators, proline and soluble protein, though they were both osmoregulatory substances, the effects of stresses on them were opposite. It suggested that cell membrane system and free water loss caused by stresses would engender different fluctuation of proline and soluble protein. For example, low temperature stress can affect the cell membrane system, and then causes a series of physiological and biochemical changes such as varieties of proline [25]. Similarly, freezing leads to excessive water loss and causes proteins denaturation as well [26]. Beyond that, the effects of combined stress on proline and soluble protein were obviously enhanced in T4. This showed that effects of freezing were more intense than those of low temperature. It might be related to restriction of gene transcription by freezing [27]. From the proline and soluble protein changes, combined stress was rather deeper influenced to alfalfa seedlings than individual basic salt stress or individual freeze-thaw stress.

\section{Discussion of Changes in Biological Membrane Permeability}

MDA is one of the main products of lipid peroxidation of plant cell membrane and the final decomposition product. Its presence in tissues is a definitive

Table 3. Pearson correlation analysis under basic salt stress and freeze-thaw stress.

\begin{tabular}{|c|c|c|c|c|c|}
\hline & Proline & Protein & MDA & SOD & POD \\
\hline Proline & 1 & -0.069 & 0.211 & 0.157 & 0.224 \\
\hline Protein & & 1 & $-0.817^{* *}$ & $-0.837^{*}$ & $-0.626^{*}$ \\
\hline MDA & & & 1 & $0.695^{* *}$ & $0.785^{*}$ \\
\hline SOD & & & & 1 & $0.776^{*}$ \\
\hline POD & & & & & 1 \\
\hline
\end{tabular}

*Correlation is significant at 0.05 lever;

**Correlation is significant at 0.01 lever. 
indicator of cell damage [28, 29]. MDA of seedlings in freeze-thaw stress increased significantly in T4, that opposed to basic salt stress, indicating the membrane lipid peroxidation caused obvious damage at frozen stage. This was consistent with Chang et al. [30] study on the mechanism of physiological and biochemical responses in seedling adaptation to below $0^{\circ} \mathrm{C}$ temperature. The effects of freeze-thaw stress were more intense than those of basic salt stress, and the effects of combined stress were stronger than individual basic salt stress or individual freeze-thaw stress. The changing trend of FT- and BS+FT stress was similar, illustrating that temperature plays a decisive role in membrane lipid peroxidation.

\section{Discussion of Changes in Antioxidant Enzymes}

The function of SOD in cells' protective enzyme system is to clear $\mathrm{O}_{2}^{-}$, and at the same time, it can make the disproportionation of product $\mathrm{H}_{2} \mathrm{O}_{2}$. The role of POD in cells' protective enzyme system is to enzymatically degrade the $\mathrm{H}_{2} \mathrm{O}_{2}$, so that plants can resist the damage of hazardous substances during metabolic processes in adversity, showing their resistance [31]. As two antioxidant enzymes, SOD and POD can protect against adverse external stressors, including extreme conditions of temperature and salt imbalance [32]. The results indicated that when seedlings were exposed to external stresses (freeze-thaw and basic salt), they would produce oxygen free radicals [33], which exacerbated membrane peroxidation and damaged the membrane system. In order to resist this change, seedlings were expected to produce a series of responses to environmental changes. In the experiment, the effects were the most intense in T4, and then SOD activity and POD activity decreased with the ascent of temperature and tended to level off. The SOD activity increased to accelerate the disproportionation of superoxide anion and scavenge superoxide free radicals, which gave rise to $\mathrm{H}_{2} \mathrm{O}_{2}$ production. POD protected cells from $\mathrm{H}_{2} \mathrm{O}_{2}$ injury. With the continuous decline of temperature, SOD and POD maintained high levels of activities, which showed the strong cold resistance of alfalfa seedlings [34].

\section{Conclusions}

Under the combined stress of freeze-thaw and basic salt, the proline related to osmotic regulation, MDA indicated by membrane lipid peroxidation, SOD activity related to oxygen free radical scavenging and POD activity related to $\mathrm{H}_{2} \mathrm{O}_{2}$ reduction, whilst soluble protein decreased. The results showed that, M. sativa CV. seedlings were more sensitive to individual basic salt stress (BS) than they were to freeze-thaw (FT) stress. Furthermore, responses of the plant to combinations of BS and FT stresses (BS+FT) were stronger than those of individual BS- or FT- stress. As a conclusion,
M. sativa planting management should avoid simultaneous occurrence of BS stress and FT stress, for example, circumventing freeze-thaw stress on seedling stage by planting $M$. sativa late in 2 weeks or improving soil quality by irrigation to reduce saline-alkali stress. It is important to point out that the experiments described here evaluated physiological responses of $M$. sativa to BS stress and FT stress in short-term laboratory simulations. It is necessary to verify the environmental applicability of these observations under long-term natural conditions.

\section{Acknowledgments}

This work was sponsored by the National Natural Science Foundation of China (Grant Nos. 31772669 and 32071874), Key Projects of Science and Technology Development Plan of Jilin Province (Grant No. 20210203001SF), Interdisciplinary Project of Jilin University (Grant No. JLUXKJC2020107) and the 111 Project (B16020).

\section{Conflict of Interest}

The authors declare no conflict of interest.

\section{References}

1. LI J., PU L., HAN M., ZHU M., ZHANG R., XIANG Y. Soil salinization research in China: Advances and prospects. Journal of Geographical Sciences, 24 (5), 943, 2014.

2. AN Y., GAO Y., ZHANG Y., TONG S., LIU X. Early establishment of Suaeda salsa population as affected by soil moisture and salinity: Implications for pioneer species introduction in saline-sodic wetlands in Songnen Plain, China. Ecological Indicators, 107, 105654, 2019.

3. YANG J., ZHANG S., LI Y., BU K., ZHANG Y., CHANG L., ZHANG Y. Dynamics of saline-alkali land and its ecological regionalization in western Songnen Plain, China. Chinese Geographical Science, 20 (2), 159, 2010.

4. QUAN W., LIU X., WANG H., CHAN Z. Physiological and transcriptional responses of contrasting alfalfa (Medicago sativa L.) varieties to salt stress. Plant Cell, Tissue and Organ Culture, 126 (1), 105, 2016.

5. MA X., REN J., DAI W., YANG W., BI Y. Effects of aluminium on the root activity, organic acids and free proline accumulation of alfalfa grown in nutrient solution. New Zealand Journal of Agricultural Research, 63 (3), 341, 2020.

6. ZHANG Q., CHEN Z., WU J., JIANG Y., YANG J., CAI S. Germplasm Screening for Salinity Tolerance at Germination and Seedling Stages in Wheat. Journal of Plant Genetic Resources, 14 (4), 620, 2013.

7. SEPEHRI A., SAMAN M., BAYAT S. Effects of $\mathrm{Na}_{2} \mathrm{CO}_{3}$ on seed germination, seed reserve utilization and seedling growth in bitter vetch (Vicia ervilia L.). Legume Research, 39 (4), 565, 2016. 
8. AUGUSTYNIAK A., PERLIKOWSKI D., RAPACZ M., KOŚCIELNIAK J., KOSMALA A. Insight into cellular proteome of Lolium multiflorum/Festuca arundinacea introgression forms to decipher crucial mechanisms of cold acclimation in forage grasses. Plant Science (Limerick), 272, 22, 2018.

9. SINGH M., KUMAR J., SINGH S., SINGH V.P., PRASAD S.M. Roles of osmoprotectants in improving salinity and drought tolerance in plants: a review. Reviews in Environmental Science and Biotechnology, 14 (3), 407, 2015.

10. KUMAR S., BEENA A.S., AWANA M., SINGH A. Physiological, Biochemical, Epigenetic and Molecular Analyses of Wheat (Triticum aestivum) Genotypes with Contrasting Salt Tolerance. Frontiers in Plant Science, 8, 1151, 2017.

11. FURLAN A.L., BIANUCCI E., GIORDANO W., CASTRO S., BECKER D. F. Proline metabolic dynamics and implications in drought tolerance of peanut plants. Plant Physiology and Biochemistry, 151, 566, 2020.

12. ABRAHAM E., HOURTON-CABASSA C., ERDEI L., SZABADOS L. Methods for determination of proline in plants. Methods in Molecular Biology (Clifton, N.J.), 639, 317, 2010.

13. MIURA K., FURUMOTO T. Cold Signaling and Cold Response in Plants. International Journal of Molecular Sciences, 14 (3), 5312, 2013.

14. DAUD M. K., HASSAN S., AZIZULLAH A., JAMIL M., REHAN N., IRUM R., QAISER M. K., ZHU S.J. Physiological, Biochemical, and Genotoxic Effects of Wastewater on Maize Seedlings. Polish Journal of Environmental Studies, 25 (2), 563, 2016.

15. WANG X., HUANG J. Principles and Techniques of Plant Physiology and Biochemical Experiment, 3rd ed.; Higher Education Press: Beijing, China, pp. 180-182, 2010 [In Chinese].

16. LATEF A.A.A., TRAN L.S.P. Impacts of Priming with Silicon on the Growth and Tolerance of Maize Plants to Alkaline Stress. Frontiers In Plant Science, 7, 243, 2016.

17. ZHAO G.M., HAN Y., SUN X., LI S.H., SHI Q.M., WANG C.H. Salinity stress increases secondary metabolites and enzyme activity in safflower. Industrial Crops and Products, 64 (1), 175, 2015.

18. CAI Q.S. Experimental of Plant Physiology, 1rd ed.; China Agricultural University Press: Beijing, China, pp. 174-178, 2013 [In Chinese].

19. GILL S.S., ANJUM N.A., GILL R., YADAV S., HASANUZZAMAN M., FUJITA M., MISHRA P., SABAT S.C., TUTEJA N. Superoxide dismutase-mentor of abiotic stress tolerance in crop plants. Environmental Science and Pollution Research International, 22 (14), 10375, 2015.

20. YUSEFI M., ASL V.N., MOHARRAMNEJAD S. Response of Oxidative Defense System to Salt-Treat in Alfalfa (Medicago Sativa L.). Fresenius Environmental Bulletin, 26 (8), 5219, 2017.
21. BIAN W., BAO G., QIAN H., SONG Z., QI Z., ZHANG M. Physiological Response Characteristics in Medicago sativa Under Freeze-Thaw and Deicing Salt Stress. Water, Air, \& Soil Pollution, 229 (6), 1, 2018.

22. POUSTINI K., SIOSEMARDEH A., RANJBAR M. Proline accumulation as a response to salt stress in 30 wheat (Triticum aestivum L.) cultivars differing in salt tolerance. Genetic Resources and Crop Evolution, 54 (5), 925, 2007.

23. MANSOUR M.M.F., ALI E.F. Evaluation of proline functions in saline conditions. Phytochemistry (Oxford), 140, 52, 2017.

24. BAO G., HE F., CHEN W., SUN J., DING X. Physiological effects of different concentrations of chloride deicing salt and freeze-thaw stress on Secale cereale L. seedlings. Journal of Plant Growth Regulation, 39 (1), 15, 2020.

25. LE GALL H., PHILIPPE F., DOMON J-M., GILLET F., PELlOUX J., RAYON C. Cell Wall Metabolism in Response to Abiotic Stress. Plants, 4 (1), 112, 2015.

26. LIU M.Z., OSBORNE C.P. Differential freezing resistance and photoprotection in C-3 and C-4 eudicots and grasses. Journal of Experimental Botany, 64 (8), 2183, 2013.

27. PU Y., LIU L., WU J., ZHAO Y., BAI J., MA L., YUE J., JIN J., NIU Z., FANG Y., SUN W. Transcriptome profile analysis of winter rapeseed (Brassica napus L.) in response to freezing stress, reveal potentially connected events to freezing stress. International Journal of Molecular Sciences, 20 (11), 2771, 2019.

28. JIANG X., QIN Y., GUO G. Effects of exogenous substances on seed germinationand chilling resistance of pepper under low temperature stress. Xinjiang Agricultural University, 50 (12), 2266, 2013 [In Chinese].

29. TSIKAS D. Assessment of lipid peroxidation by measuring malondialdehyde (MDA) and relatives in biological samples: Analytical and biological challenges. Analytical Biochemistry, 524, 13, 2017.

30. CHANG Y., ZHANG J., BAO G., YAN B., QU Y., ZHANG M. Physiological Responses of Highland Barley Seedlings to $\mathrm{NaCl}$, Drought, and Freeze-Thaw Stress. Journal of Plant Growth Regulation, 40 (1), 154, 2021.

31. AHANGER M.A., AKRAM N.A., ASHRAF M., ALYEMENI M.N., WIJAYA L., AHMAD P. Plant responses to environmental stresses-from gene to biotechnology. AoB Plants, 9 (4), plx025, 2017.

32. ZANG D., WANG C., JI X., WANG Y. Tamarix hispida zinc finger protein ThZFP1 participates in salt and osmotic stress tolerance by increasing proline content and SOD and POD activities. Plant Science, 235, 111, 2015.

33. GAI Y., DONG B., WEI J. Reseach on Physiological and Biochemical Index Reponse of Halophytes and Non-Salt Plants under Mixed Saline-alkali Stress. Journal of Jilin Agricultural University, 35 (02), 132, 2013 [In Chinese].

34. SONG Y.G., LV J., MA Z. Q., DONG W. The mechanism of alfalfa (Medicago sativa L.) response to abiotic stress. Plant Growth Regulation, 89 (3), 239, 2019. 